\title{
Spray-drying of alumina powder for APS: effect of slurry properties and drying conditions upon particle size and morphology of feedstock
}

\author{
BAI YU, YANG JIAN FENG*, LEE SOO WOHN ${ }^{\dagger}$, CHEN HUANG ${ }^{\dagger}$, \\ YU FANG LI and ZHANG JIA ${ }^{\dagger}$ \\ State Key Laboratory for Mechanical Behavior of Materials, Xi'an Jiaotong University, Xi'an 710049, P.R. China \\ ${ }^{\dagger}$ Department of Materials Engineering. Sun Moon University, Korea
}

MS received 27 January 2010; revised 7 September 2010

\begin{abstract}
In this paper, effects of variables concerning slurry properties and drying conditions on the particle size and morphology of feedstock were discussed. The results indicated that, the increase of powder loading increased $D_{50}$ and volume content but reduced recovery rate slightly. Other variables, such as inlet temperature, showed a maximum on the desired property. The particle size of resulting feedstock increased with the rise of feeding rate of slurry, however, decreased with the increase of atomization pressure based on the premise that atomization pressure was enough to force slurry to form the liquid membrane. For preparation of spherical feedstock, optimized variables were as follows: $60 \mathrm{wt} \%$ powder in slurry, 2 wt.\% PVA in slurry,

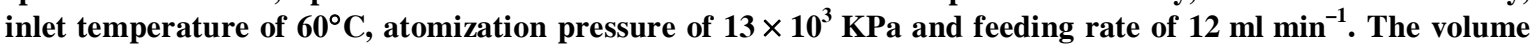
content of feedstocks with 10-45 $\mu \mathrm{m}$ was above $65 \%$ and for $D_{50}$ it was $15.42 \mu \mathrm{m}$. In addition, according to the heat and mass transfer equation, the drying mechanism was established, which was well in agreement with the experimental results.
\end{abstract}

Keywords. Spray drying; feedstock; particle size; morphology.

\section{Introduction}

Alumina $\left(\mathrm{Al}_{2} \mathrm{O}_{3}\right)$ coating exhibits a beneficial combination of properties such as high hardness, chemical resistance and low thermal conductivity, which has been studied for a number of applications (Kathrein et al 2003; Edlmayr et al 2010). And there is a need to enhance the performance of $\mathrm{Al}_{2} \mathrm{O}_{3}$ coating by choosing the preparation technology. Atmospheric plasma spray (APS) is a widely used method for preparation of $\mathrm{Al}_{2} \mathrm{O}_{3}$ coating due to its high melting point, which can provide coatings with good adherence to the substrate and a lower level of porosity. During the spraying process, the feedstock is melted and accelerated against the substrate to form a compact coating in plasma jet. Meanwhile, individual nanoparticle cannot be directly sprayed because of its low mass and bad fluidity to be carried in a moving gas stream and deposited on the substrate. So it is necessary for reconstituting nanoparticles into micrometer-sized feedstocks. Effects of particle size and morphology of feedstock on the quality of as-sprayed coatings should be taken into account (Kollenberg and Decker 1993). Two types of methods are generally used to prepare feed-

*Author for correspondence (yang155@ mail.xjtu.edu.cn) stocks: fused and crushed or spray drying. The latter one has numerous advantages, and some of them are to present spherical morphologies and homogeneous composition of different materials, which are regarded as ideal method not only for APS but also for sintering of ceramic (Keller et al 2003; Roy et al 2005).

Spray drying is a process by which a water-based suspension (slurry) is transformed into a dry granule (feedstock) by spraying the fluid feed material into a stream of heated air. Spray drying enables the fabrication of composite powder by aggregation of different small particles using an appropriate organic binder. The rapid heat and mass transfer occurs during the process. The resulting feedstocks always have a large variety of shapes: from elongated, pancake, donut-shaped, needlelike or hollow granules to uniform solid spheres according to slurry properties and drying conditions. That is to say, both can greatly affect the morphology of feedstocks (Walton and Mumford 1999; Liang et al 2001; Mahdjouba et al 2003; Bertrand et al 2005).

The objective of this study is to systematically assess the effect of slurry properties (contents of powder and binder) and drying conditions (inlet temperature, feeding rate and atomization pressure) upon the morphology and particle size of feedstocks. Scanning electron microscopy (SEM) and laser particle size analyser (LPSA) were used 
to observe the morphology and analyse particle size of collected feedstocks after drying, respectively. Furthermore, according to the heat and mass transfer equations, theoretical calculation about effect of some variables on the particle size of feedstocks was carried out.

\section{Experimental}

\subsection{Materials and slurry preparation}

Commercial $\alpha-\mathrm{Al}_{2} \mathrm{O}_{3}$ powder with an average grain size 100-150 nm (Sumitomo Chemical Co. Ltd., Japan) was used in the present study. A very strict mixing procedure was carried out. A specific amount of hydrosoluble polyvinyl alcohol (PVA) (Junsel Chemical Co. Ltd., Japan) as binder was first added to distilled water and stirred for 20 min at $60^{\circ} \mathrm{C}$ until PVA was completely soluble. Then the $\alpha-\mathrm{Al}_{2} \mathrm{O}_{3}$ powder was gradually added and the suspension was stirred again for an additional $15 \mathrm{~min}$ and then ball-milled for more than $24 \mathrm{~h}$ to achieve well stabilized and dispersed slurry.

\subsection{Spray drying}

EYEL4 SD-1000 spray drier (Japan) with a pneumatic nozzle was used in this study. The heated air was used as the drying medium in the drying chamber. Drying conditions such as inlet temperature, feeding rate and atomization pressure were controlled during the spray drying. Finally, the feedstocks were collected in the collecting chamber from the cyclone.

\subsection{Feedstock characterization}

The feedstocks after heating at $80^{\circ} \mathrm{C}$ for $12 \mathrm{~h}$ in the oven were observed by scanning electron microscopy (SEM). And the particle sizes were analysed by laser particle size analyser (LPSA). In addition, considering the high melting point of $\mathrm{Al}_{2} \mathrm{O}_{3}$, the optimal particle size range of feedstocks was 10-45 $\mu \mathrm{m}$ for APS (Davis 2004). So, in this paper, the volume contents of $10-45 \mu \mathrm{m}$ feedstocks were calculated according to LPSA and named as 'volume content' for the reason of simplicity.

\section{Results and discussion}

\subsection{Morphology of starting powder and feedstock}

Figure 1 shows the starting $\alpha-\mathrm{Al}_{2} \mathrm{O}_{3}$ powder used for spray drying. As shown in it, the grain size was in the range of $100-150 \mathrm{~nm}$, which could not be carried in a moving gas stream and deposited on the substrate in the APS process because of the low mass and bad fluidity. Figure 2 shows the morphology of feedstock after spray drying, which enables the fabrication of granules by aggregation of nano $\alpha-\mathrm{Al}_{2} \mathrm{O}_{3}$ powder using PVA as organic binder. Compared with the above two figures, it was found that the grain size of $\alpha-\mathrm{Al}_{2} \mathrm{O}_{3}$ powder was not changed since the temperature of spray drying was low (generally lower than $200^{\circ} \mathrm{C}$ ). Meanwhile, as shown in figure 2, there existed two different morphologies after spray drying. One was spherical (marked as A), the other was donut-shaped (marked as B). The forming reason of donut-shaped feedstock was discussed in detail later.

\subsection{Atomization pressure and feeding rate of slurry}

Figure 3 shows the volume content of 10-45 $\mu \mathrm{m}$ feedstock (written as 'volume content' for simplicity in the latter sections of this paper) and median particle size $D_{50}$ under different atomization pressures. As shown in the figure, $D_{50}$ was increased with the rise of volume content. Furthermore, when the atomization pressure was $13 \times 10^{3} \mathrm{KPa}$,

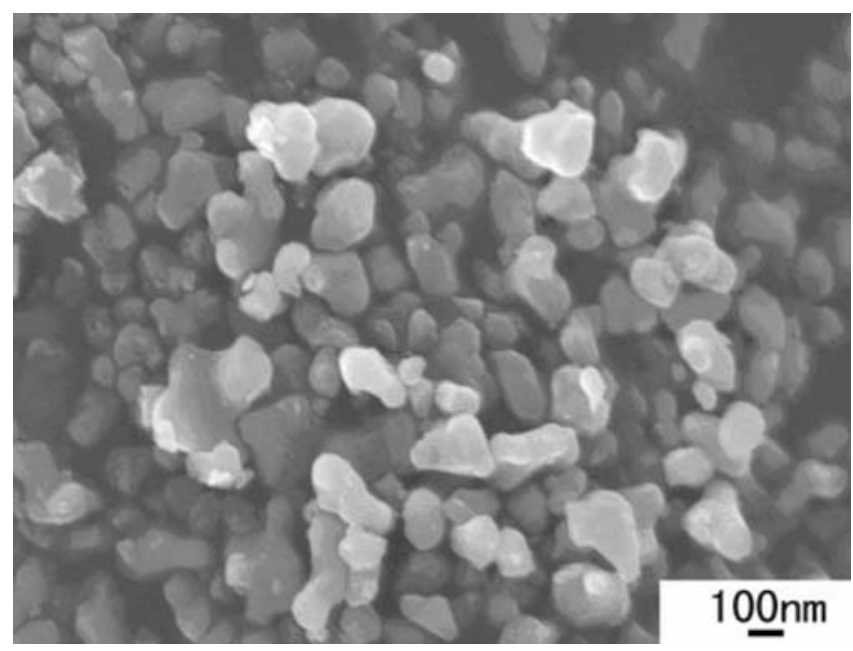

Figure 1. Starting $\alpha-\mathrm{Al}_{2} \mathrm{O}_{3}$ powder used for spray drying.

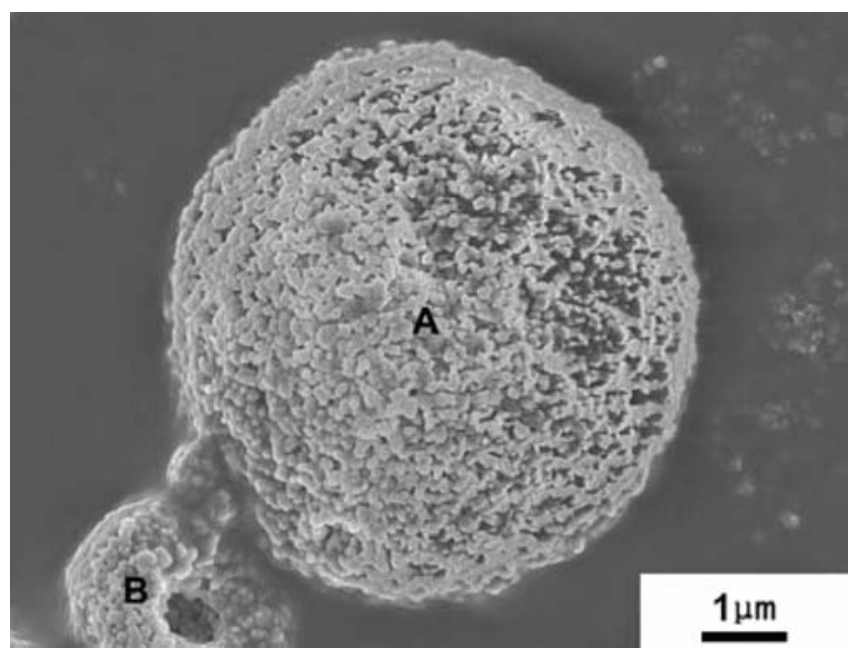

Figure 2. Morphology of $\alpha-\mathrm{Al}_{2} \mathrm{O}_{3}$ feedstocks for APS after spray drying. 
both the volume content and $D_{50}$ reached the highest points, respectively afterwards decreased gradually with the rise of atomization pressure. The morphology of resulting feedstock is shown in figure 4 . It can be seen that the particle size of all feedstocks was $<40 \mu \mathrm{m}$, which was the reason why $D_{50}$ increased with the rise of volume content. In addition, the spherical and donut-shaped feedstocks co-existed after spray drying. Figure 5 shows the volume content and $D_{50}$ under different feeding rates of slurry. As shown in it, the volume content and $D_{50}$ went up dramatically with the increase of feeding rate of slurry.

Generally, the whole spray drying process can be divided into three steps: (i) formation of droplets after the slurry passing the pneumatic nozzle, which was located at the top of drying chamber; (ii) evaporation of water in droplets and formation of feedstock in the drying chamber and (iii) collection of feedstock in collecting chamber. Atomization pressure and feeding rate of slurry played an important role in step 1. Figure 6 is the schematic diagram of pneumatic external mixing nozzle and formation of droplets. As shown in the figure, when the slurry was forced by the compressed air to pass the pneumatic nozzle, air cone covered by liquid membrane was formed. And the liquid membrane would split to droplets under gravity. The cone angle was defined as atomizing angle. Some investigators (Gretzinger and Marshall 1961) studied the characteristics of mean droplet size and droplet size distribution for a pneumatic external mixing nozzle and gave the following equation:

$$
D_{50}=2600\left[\left(\frac{M_{\mathrm{L}}}{M_{\mathrm{a}}}\right)\left(\frac{\eta_{\mathrm{a}}}{G_{\mathrm{a}} L_{\mathrm{c}}}\right)\right]^{0 \cdot 4},
$$

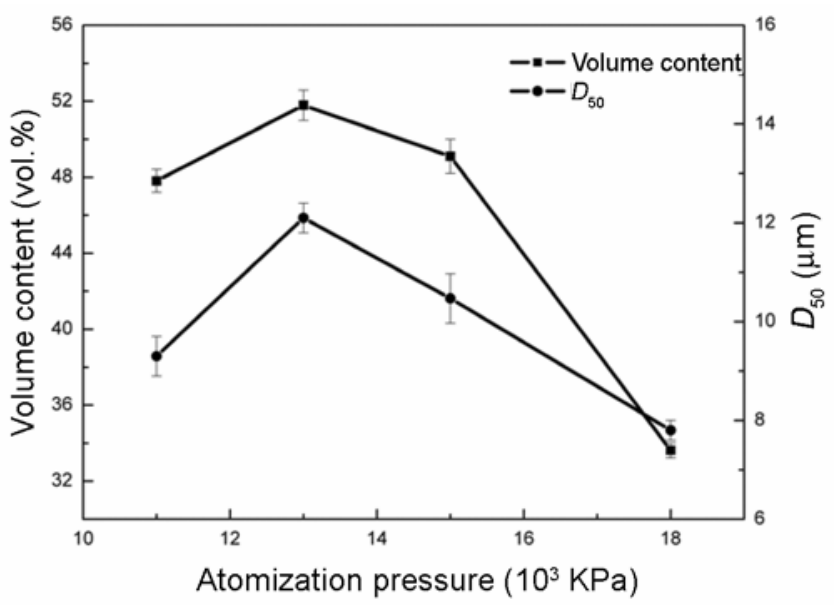

Figure 3. Atomization pressure vs volume content and $D_{50}$, other variables were powder content: $60 \mathrm{wt} . \%$, PVA content: $5 \mathrm{wt} \%$, inlet temperature: $160^{\circ} \mathrm{C}$ and feeding rate: $12 \mathrm{ml} \mathrm{min}^{-1}$. where $D_{50}$ is mean droplet size $(\mu \mathrm{m}), M_{\mathrm{L}}$ and $M_{\mathrm{a}}$ are the mass rate of liquid and atomization air $(\mathrm{kg} / \mathrm{h}), \eta_{\mathrm{a}}$ the air viscosity $(p), G_{\mathrm{a}}$ the mass flow of air per area gas jet orifice at the nozzle outlet $\left(\mathrm{g} \mathrm{cm}^{-2} \mathrm{~s}^{-1}\right)$ and $L_{\mathrm{c}}$ a characteristic length of nozzle $(\mathrm{cm})$. Meanwhile, according to the work of Gretzinger and Marshall (1961), $D_{50}$ mainly depended on the $M_{\mathrm{L}} / M_{\mathrm{a}}$ ratio. And as seen from (1), an increase of $M_{\mathrm{L}} / M_{\mathrm{a}}$ ratio will increase $D_{50}$. In the atomization process of slurry, the mass rate of liquid $M_{\mathrm{L}}$ was directly proportional to the feeding rate of slurry, while mass rate of atomization air $M_{\mathrm{a}}$ increased with the rise of atomization pressure. So, either an increase in feeding rate of suspension or decrease of atomization pressure will increase the $M_{\mathrm{L}} / M_{\mathrm{a}}$ ratio as well as the droplet size. Since diameter of droplet had direct relation to the particle size of feedstock after spray drying, decrease of atomization pressure could increase the particle size of feedstock and the particle size of feedstock increased with the rise of feeding rate of slurry. The above result was also in agreement of previous work of others (Hede et al 2008). However, it was pointed out that if the atomization pressure was too low to force enough slurry to form the liquid membrane, the diameter of droplet or the particle size of feedstock would go down, which was confirmed by the result shown in figure 3. For example, when the atomization pressure was $11 \times 10^{3} \mathrm{KPa}$, the volume content and $D_{50}$ were $47.8 \mathrm{vol} . \%$ and $9.3 \mu \mathrm{m}$, respectively which were lower than those at the atomization pressure of $13 \times 10^{3} \mathrm{KPa}$.

\subsection{Powder content in slurry and inlet temperature}

Figure 7 shows the volume content and $D_{50}$ at different inlet temperatures (considered as the temperature of heated air). As shown in it, when the atomization pressure was $160^{\circ} \mathrm{C}$, the volume content or $D_{50}$ reached the highest point, afterward decreased evidently with the rise of inlet temperature since the evaporation time of water in the droplets was reduced greatly and burst of feedstocks (as described later). Otherwise, the volume content and $D_{50}$ under different powder contents in slurry were shown figure 8. It was found that the volume content and $D_{50}$ went up dramatically with the rise of powder content in the slurry. Meanwhile, the morphologies of resulting feedstocks are shown in figure 9. It could be seen that the particle size of feedstocks went up greatly with the increase of powder content in the slurry, which was in agreement with the results obtained by LPSA.

As mentioned above, there were three steps in the spray drying process. And the inlet temperature and powder content in the slurry had an important effect on step ii: evaporation of water in droplets and formation of feedstock in the drying chamber. The heat and mass transfer process of one single droplet in the drying chamber was analysed. The following equation described the process that the water in the droplet transferred to the heated air. 
Table 1. Optimal variables for spray drying.

\begin{tabular}{lccccc}
\hline Variables & $\begin{array}{c}\text { Powder } \\
\text { content }(\text { wt. } \%)\end{array}$ & $\begin{array}{c}\text { PVA } \\
\text { content }(\text { wt.\% })\end{array}$ & $\begin{array}{c}\text { Inlet temperature } \\
\left({ }^{\circ} \mathrm{C}\right)\end{array}$ & $\begin{array}{c}\text { Feeding rate } \\
\left(\mathrm{ml} \mathrm{min}^{-1}\right)\end{array}$ & $\begin{array}{c}\text { Atomization } \\
\text { pressure }\left(10^{3} \mathrm{KPa}\right)\end{array}$ \\
\hline Value & 60 & 2 & 160 & 12 & 13 \\
\hline
\end{tabular}
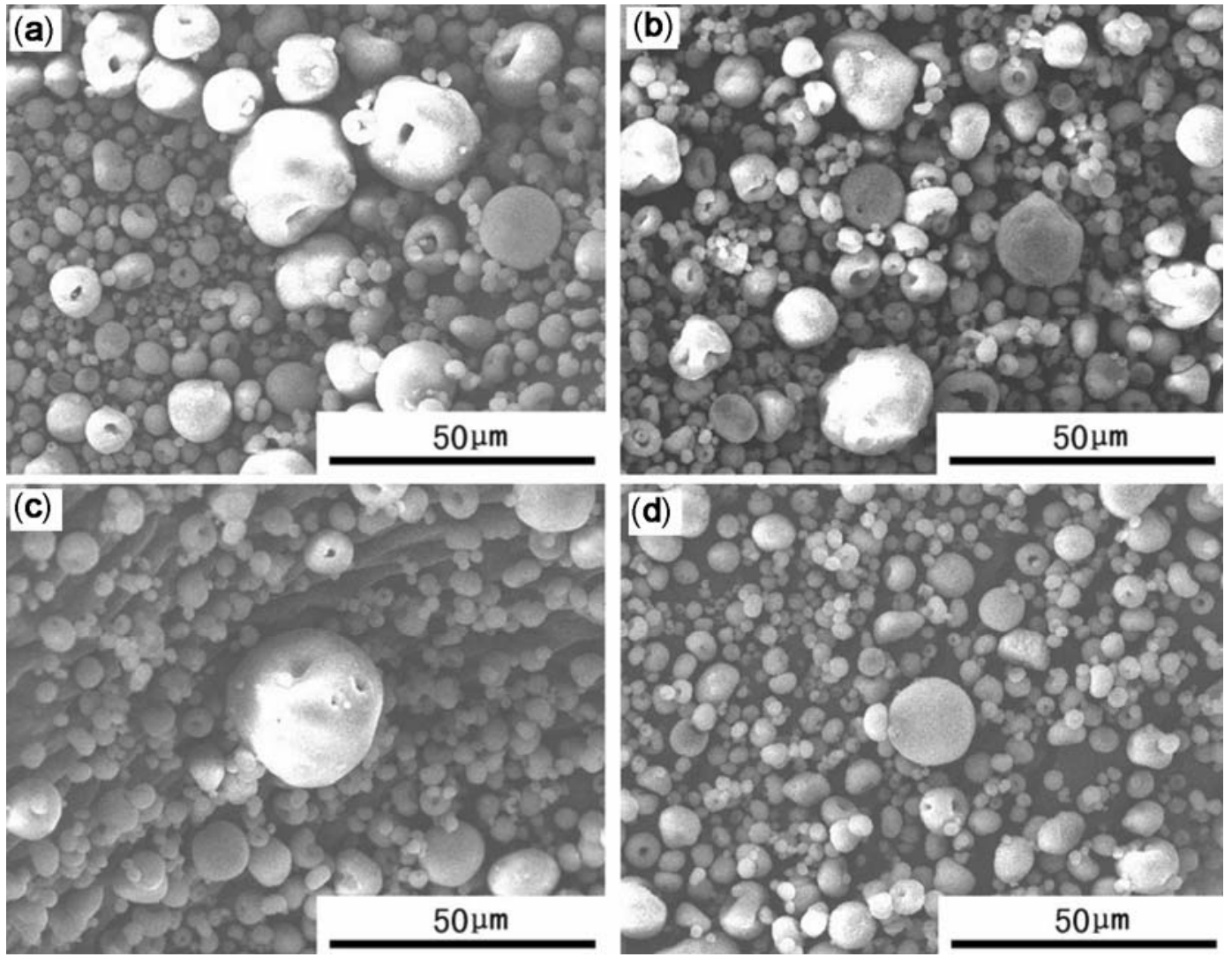

Figure 4. Morphology of feedstock prepared under different atomization pressures. (a) $11 \times 10^{3} \mathrm{KPa}$, (b) $13 \times 10^{3} \mathrm{KPa}$, (c) $15 \times 10^{3} \mathrm{KPa}$ and (d) $18 \times 10^{3} \mathrm{KPa}$.

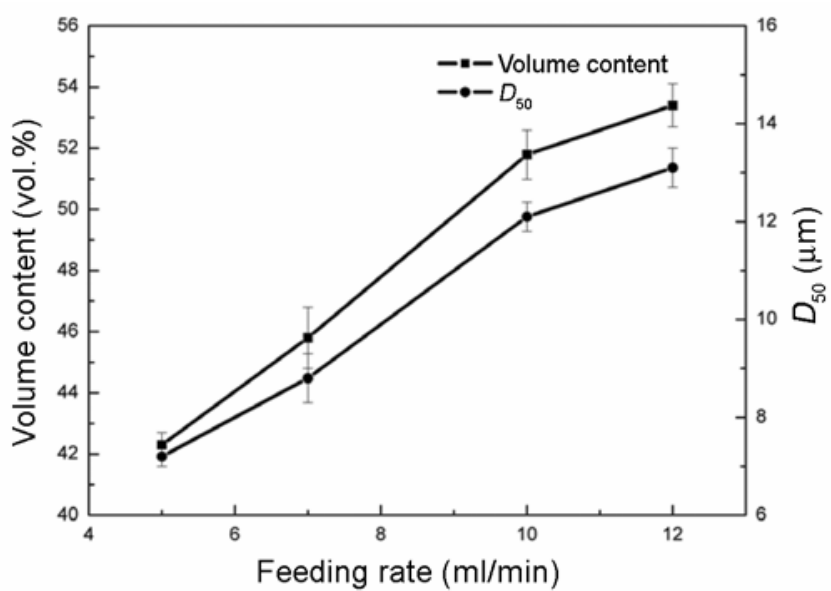

Figure 5. Feeding rate of slurry vs volume content and $D_{50}$, other variables were powder content: $60 \mathrm{wt} . \%$, PVA content: $5 \mathrm{wt} . \%$, inlet temperature: $160^{\circ} \mathrm{C}$ and atomization pressure: $13 \times 10^{3} \mathrm{KPa}$.

$$
d w / d t=K_{\mathrm{x}} A_{\mathrm{m}}\left(X_{\mathrm{w}}-X\right),
$$

where $w$ is the amount of evaporated water $(\mathrm{g}), t$ the evaporation time $(\mathrm{s}), K_{\mathrm{x}}$ the mass transfer coefficient $\left(\mathrm{gm}^{-2} \mathrm{~s}^{-1}\right), A_{\mathrm{m}}$ the mass transfer area $\left(\mathrm{m}^{2}\right), X_{\mathrm{w}}$ the saturated water content of air on the surface of droplet (wt.\%) and $X$ the water content of heated air (wt.\%).

Meanwhile, the heat was transferred from heated air to a droplet. The heat transfer equation was as follows:

$$
d Q / d t=a A_{\mathrm{t}} \Delta T
$$

where $Q$ is heat transfer quantity $(\mathrm{J}), a$ the heat transfer coefficient $\left(\mathrm{J} \mathrm{m}^{-2} \mathrm{~s}^{-1} \mathrm{~K}^{-1}\right)$ and $A_{\mathrm{t}}$ the heat transfer area $\left(\mathrm{m}^{2}\right)$.

Supposing the heat transferred from heated air to a droplet should equal the vaporization heat of droplet, i.e.

$d Q / d t=a A \Delta T=-d w / d t R$, 
where $R$ is the vapourization heat per unit mass $\left(\mathrm{J} \mathrm{kg}^{-1}\right)$, $w$ the water evaporation quantity $(\mathrm{kg})$ and $\Delta T$ is the temperature difference between the droplet and ambient $(\mathrm{K})$. The following relation was obtained:

$$
-d w=(a A \Delta T / R) d t .
$$

At the same time, there exists the following relations:

$$
\begin{aligned}
& w=\frac{\pi D^{3} V_{\mathrm{L}} \rho_{\mathrm{L}}}{6}, \\
& d w=\frac{\pi D^{2} V_{\mathrm{L}} \rho_{\mathrm{L}}}{2} \mathrm{~d} D,
\end{aligned}
$$

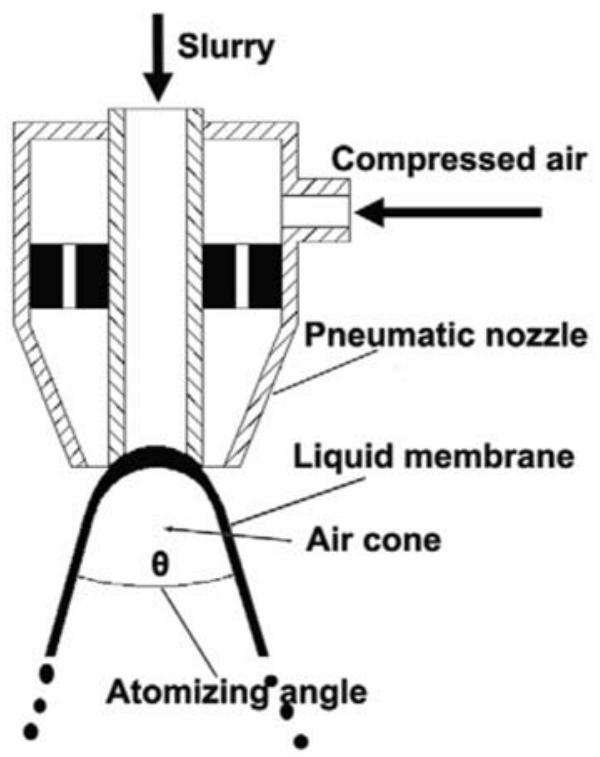

Figure 6. Schematic diagram of pneumatic nozzle and formation of droplets.

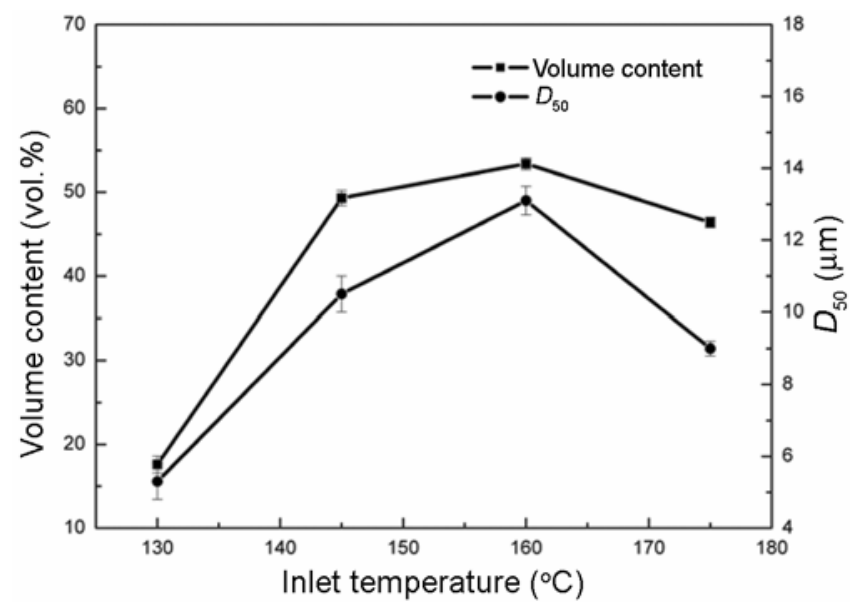

Figure 7. Inlet temperature vs volume content and $D_{50}$, other variables were powder content: $60 \mathrm{wt} . \%$, PVA content: $5 \mathrm{wt} . \%$, atomization pressure: $13 \times 10^{3} \mathrm{KPa}$ and feeding rate: $12 \mathrm{ml} \mathrm{min}^{-1}$.

$$
\begin{aligned}
& A=\pi D^{2}, \\
& a=2 \lambda / D,
\end{aligned}
$$

where $D$ is the diameter of droplet, $V_{\mathrm{L}}$ the volume content of water in slurry (vol.\%), $\rho_{\mathrm{L}}$ the water density $\left(\mathrm{kg} \mathrm{m}^{-3}\right)$ and $\lambda$ the heat conductivity of water $\left(\mathrm{Jm}^{-1} \mathrm{~s}^{-1} \mathrm{~K}^{-1}\right)$.

Substitute (7), (8) and (9) for (4), it yields:

$$
\begin{aligned}
& d t=-\frac{R D V_{\mathrm{L}} \rho_{\mathrm{L}}}{4 \lambda \Delta T} d(D), \\
& \int_{D_{0}}^{D_{1}}-D d(D)=\int_{t_{0}}^{t_{1}} \frac{4 \lambda \Delta T}{R V_{\mathrm{L}} \rho_{\mathrm{L}}} \mathrm{d} t, \\
& D_{1}^{2}=D_{0}^{2}-\frac{8 \lambda \Delta T}{R V_{\mathrm{L}} \rho_{\mathrm{L}}}\left(t_{1}-t_{0}\right),
\end{aligned}
$$

where $D_{0}$ is the diameter of original droplet $(\mathrm{m}), D_{1}$ the diameter of droplet after complete evaporation of water $(\mathrm{m}), t_{0}$ and $t_{1}$ are evaporation beginning and stopping time, respectively.

Supposing the evaporation time $t=t_{1}-t_{0}$, which is a function of $V_{\mathrm{L}}$ and $T_{\mathrm{in}}$, it yields:

$$
t=B \times \frac{V_{\mathrm{L}}^{m}}{T_{\mathrm{in}}^{n}},
$$

where $B$ is a constant, $T_{\text {in }}$ the inlet temperature, it yields

$$
D_{1}^{2}=D_{0}^{2}-F \frac{V_{\mathrm{L}}^{m-1}}{T_{\mathrm{in}}^{n}},
$$

where $F=8 \lambda \Delta T B / R \rho_{\mathrm{L}}$.

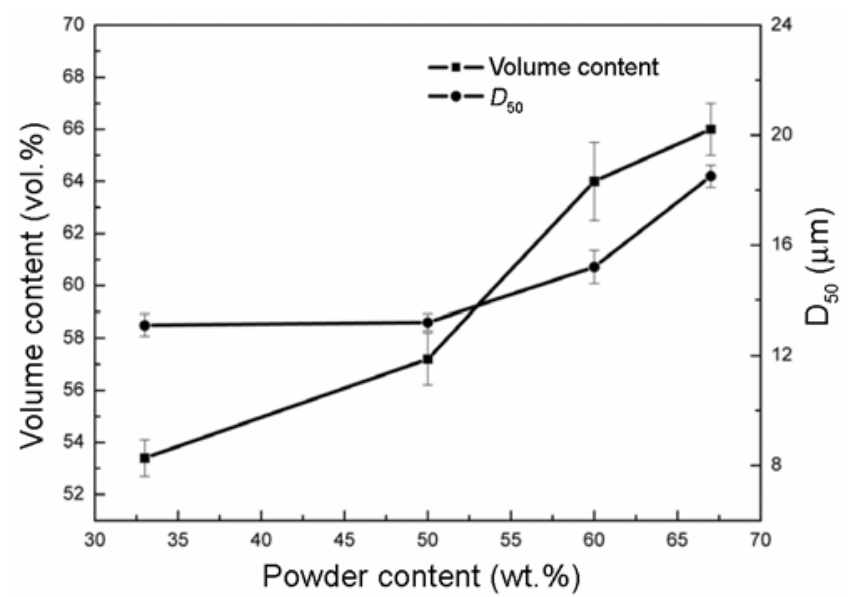

Figure 8. Powder content vs volume content and $D_{50}$, other variables were PVA content: $5 \mathrm{wt} \%$, inlet temperature: $160^{\circ} \mathrm{C}$, atomization pressure: $13 \times 10^{3} \mathrm{KPa}$ and feeding rate: $12 \mathrm{ml} \mathrm{min}^{-1}$. 

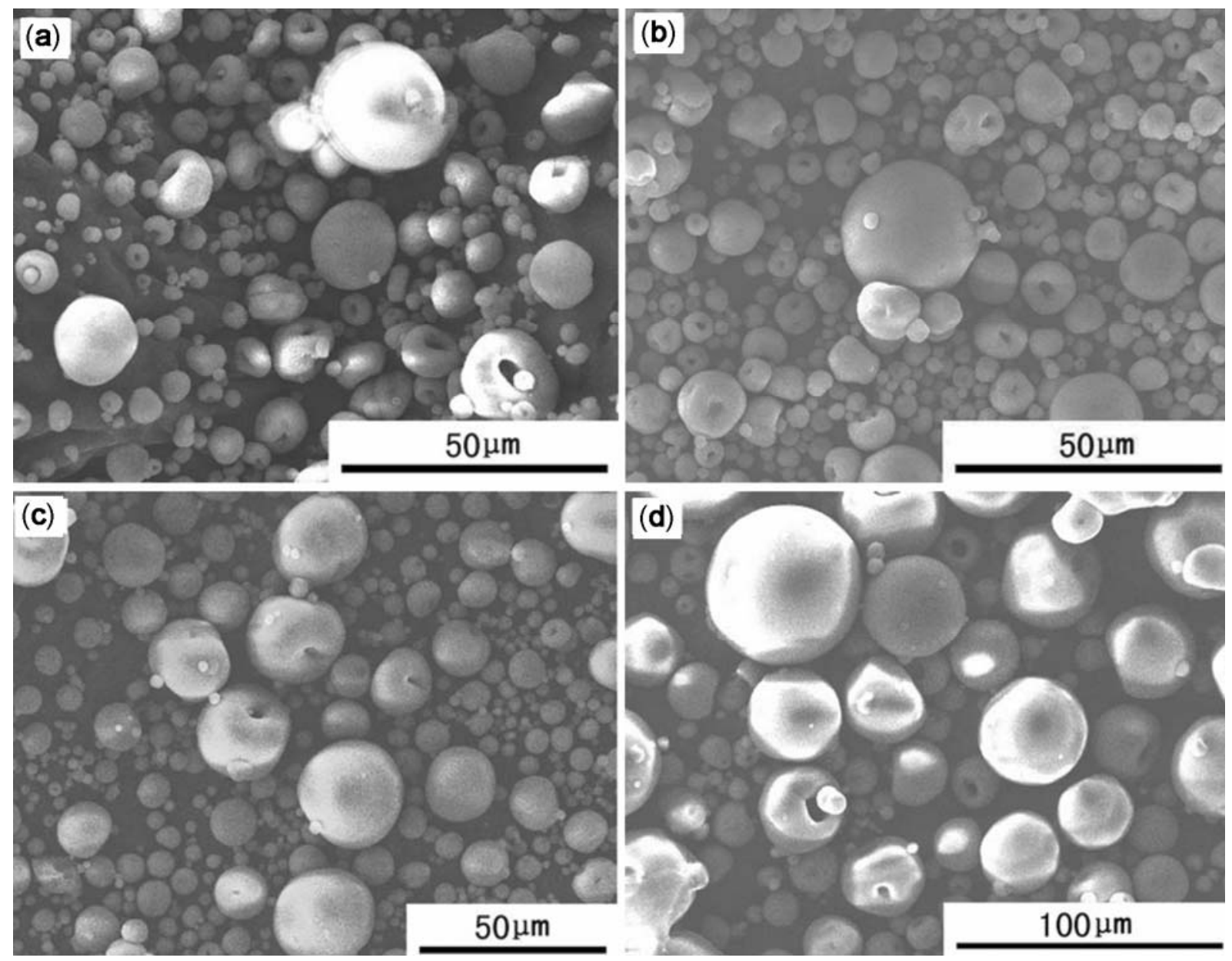

Figure 9. SEM images of feedstocks with different powder contents in slurry: (a) 33 wt. $\%$, (b) 50 wt. $\%$, (c) 60 wt. $\%$ and (d) 67 wt.\%.

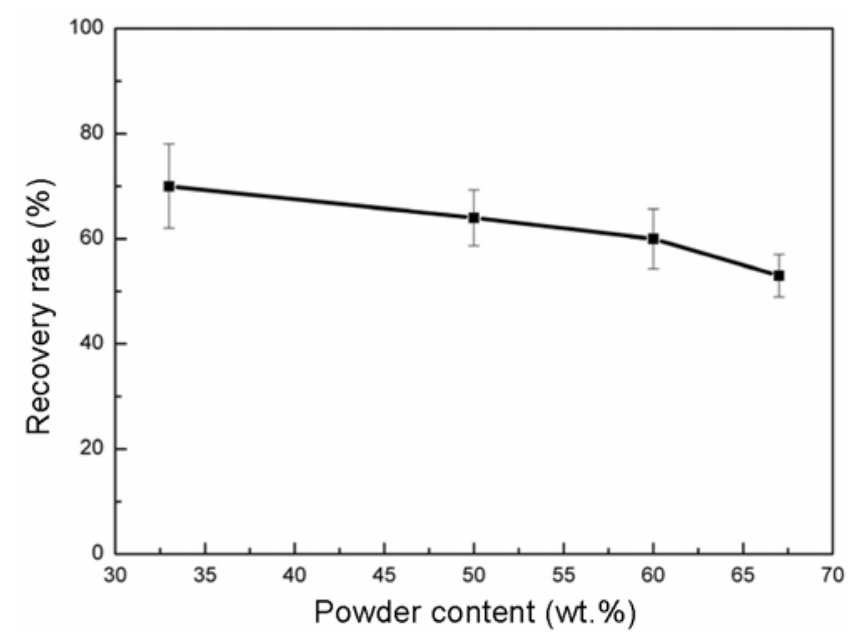

Figure 10. Powder content vs recovery rate.

Since $V_{\mathrm{p}}=1-V_{\mathrm{L}}$ in one droplet, $V_{\mathrm{p}}$ is the powder content in the slurry, it finally yields:

$$
D_{1}^{2}=D_{0}^{2}-F \frac{\left(1-V_{\mathrm{P}}\right)^{m-1}}{T_{\mathrm{in}}^{n}} .
$$

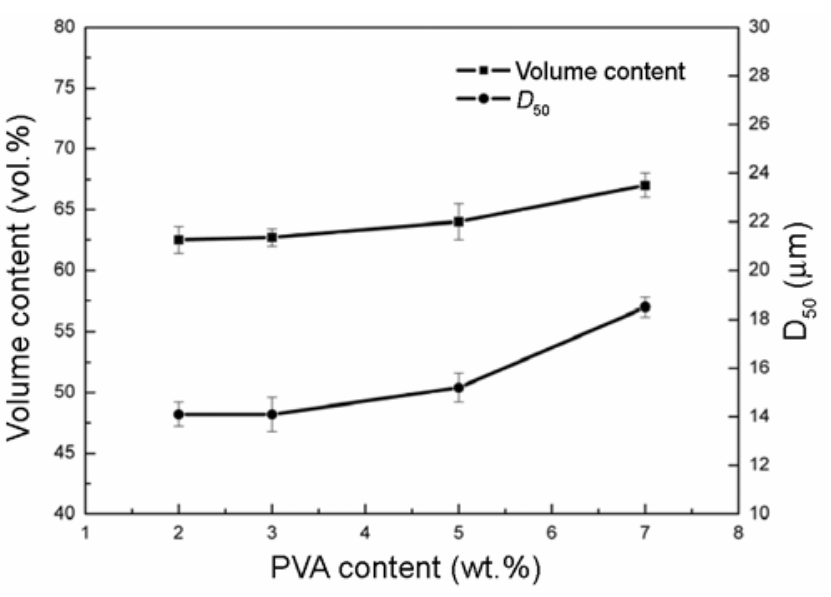

Figure 11. PVA content in slurry vs volume content and $D_{50}$, other variables were powder content: $60 \mathrm{wt} \%$, inlet temperature: $160^{\circ} \mathrm{C}$, atomization pressure: $13 \times 10^{3} \mathrm{KPa}$ and feeding rate: $12 \mathrm{ml} \mathrm{min}^{-1}$.

As shown in (15), the diameter of feedstock after spray drying had a direct relation to that of original droplet and increased with the rise of powder content in the slurry 

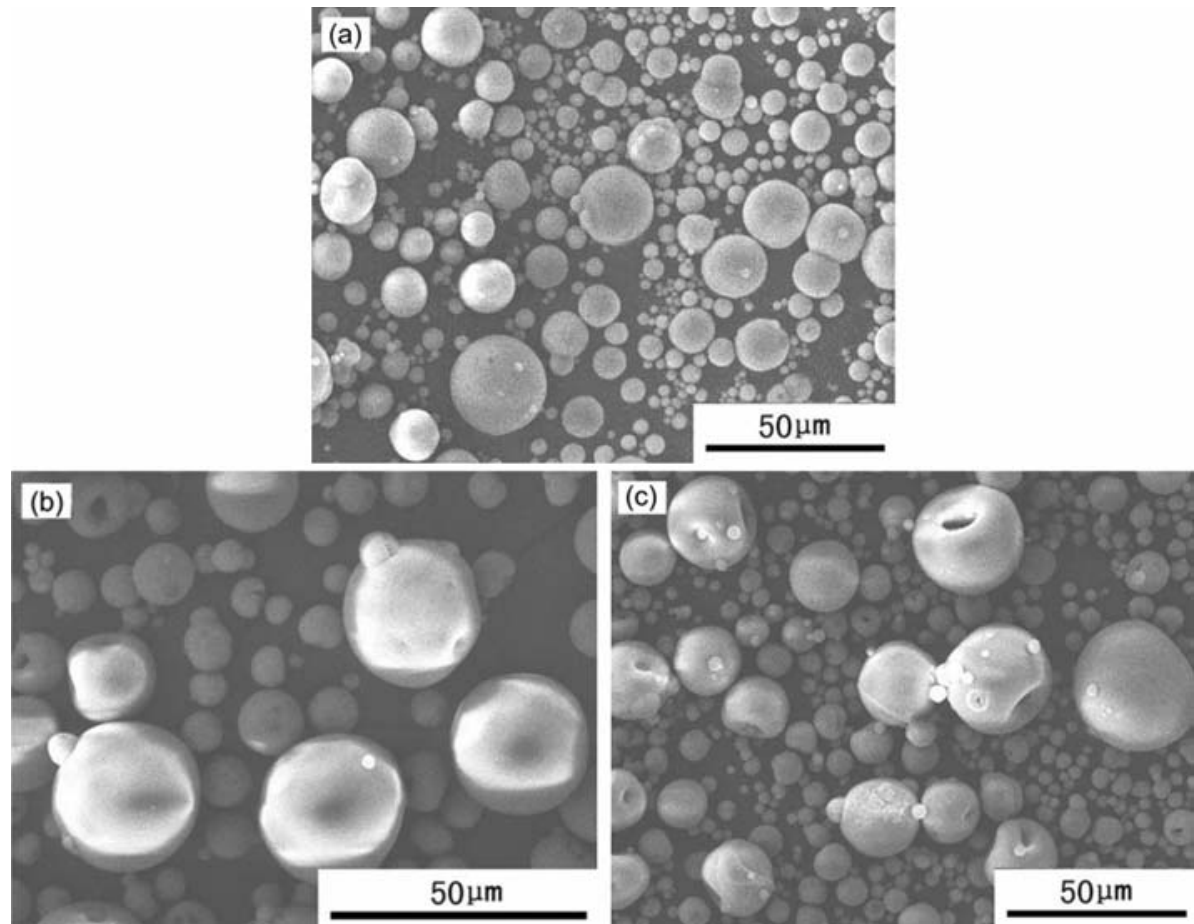

Figure 12. SEM images of feedstocks with different PVA contents in slurry: (a) 2 wt.\%, (b) 3 wt. $\%$ and (c) 7 wt. $\%$.

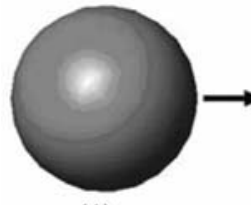

(1)

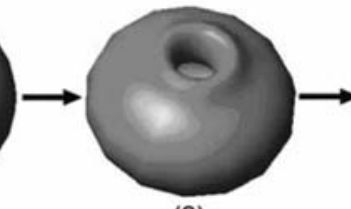

(2)

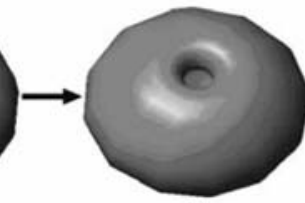

(3)

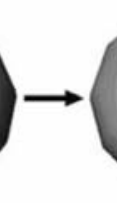

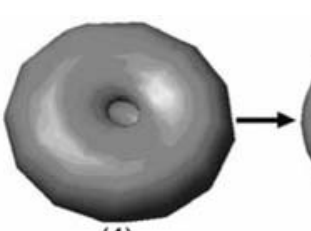

(4)

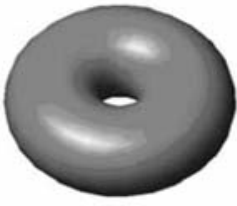

(5)

Figure 13. Schematic diagram of formation process of donut-shaped feedstock.

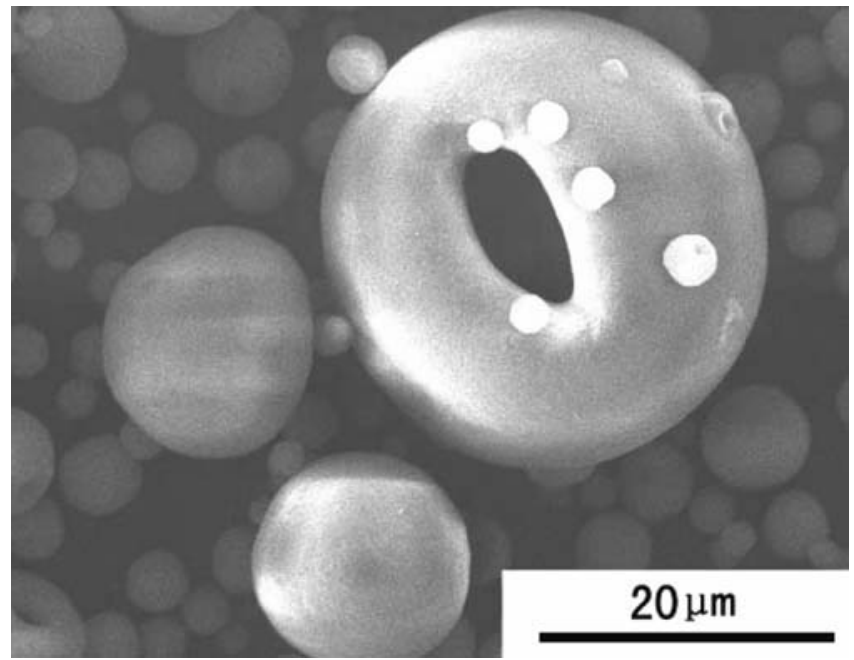

Figure 14. SEM image of typical donut-shaped feedstock.

and inlet temperature (on the premise that it was lower than $160^{\circ} \mathrm{C}$ ), which was well in agreement with the above experimental results.
However, one problem with respect to recovery rate should be considered. In this study, the recovery rate was defined as:

$$
R=W_{1} / W_{0},
$$

where $R$ is the recovery rate, $W_{1}$ the weight of feedstock after heating at $80^{\circ} \mathrm{C}$ for $12 \mathrm{~h}$ in the oven $(\mathrm{g}), W_{2}$ the weight of starting $\alpha-\mathrm{Al}_{2} \mathrm{O}_{3}$ powder $(\mathrm{g})$. The relation between powder content in slurry and recovery rate is shown in figure 10. As seen in it, recovery rate went down with the rise of powder content in slurry, which was due to a great deal of powder stuck to the wall of drying chamber during the spray drying process.

\subsection{PVA content in slurry}

Figure 11 shows the volume content and $D_{50}$ of feedstocks with different PVA (as binder) contents in the slurry. As shown in it, the volume content and $D_{50}$ increased slightly with the rise of PVA content in the slurry, indicating that in the range of $2-7 \mathrm{wt} . \%$, PVA content 


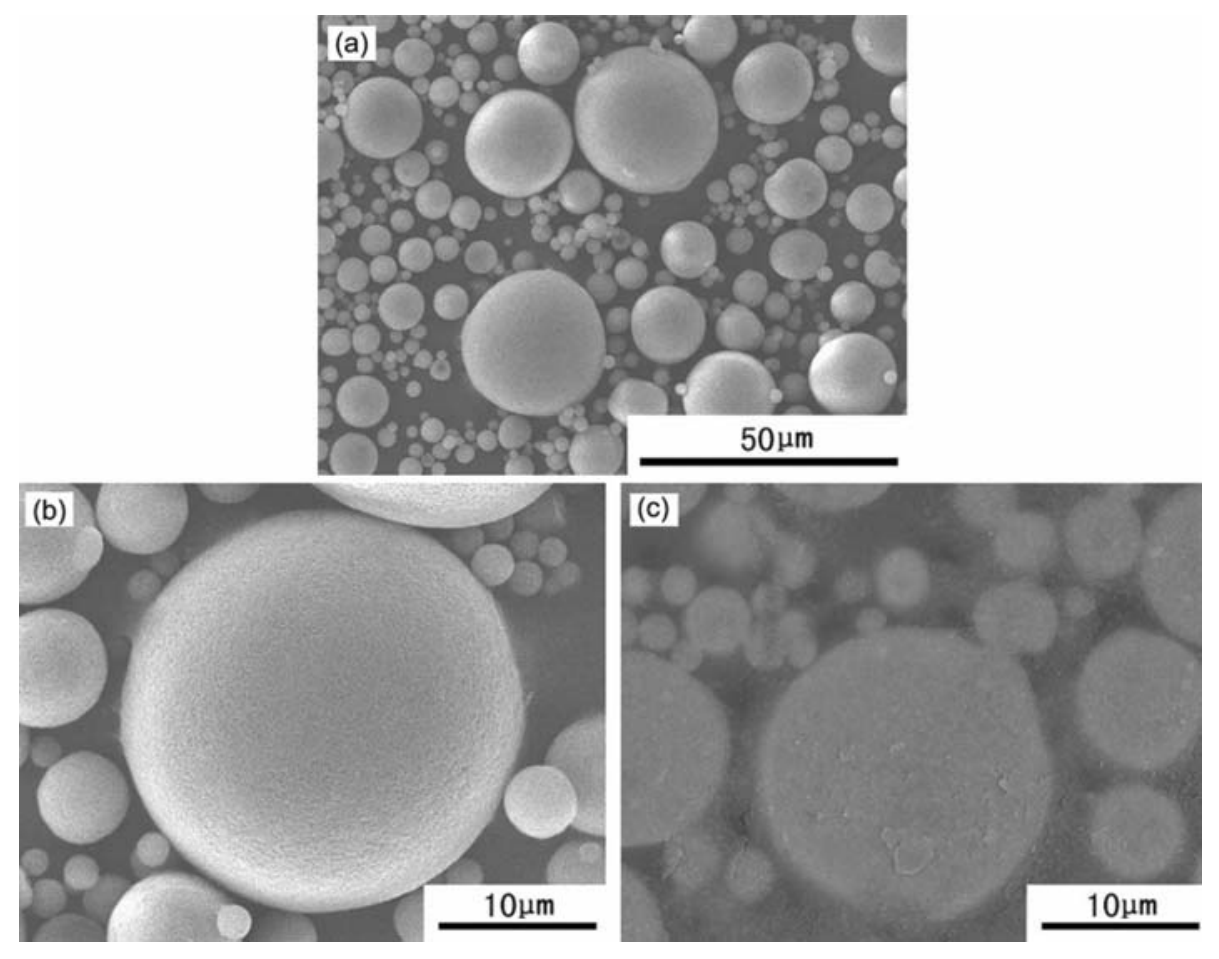

Figure 15. SEM images of feedstocks after spray drying with optimal variables: (a) morphology of feedstocks, (b) local amplification of (a) and (c) cross-section of (b).

played a less important role in the particle size of feedstock. Figure 12 shows SEM images of feedstocks with different PVA contents in slurry. As seen from it, an increase of PVA content in slurry can greatly improve the formation of donut-shaped feedstocks.

It was previously proposed that one simple mechanism could describe the formation of donut-shaped feedstock (Cao et al 2000). Figure 13 is the schematic diagram. When the slurry was forced into the drying chamber, it was separated into small droplets immediately by the compressed air, as shown in step 1 in figure 13. Afterwards, the droplet shrank due to the fast evaporation of water in slurry with the action of heated air. During the process of moisture moving from the inside to the outside of the droplet, the powder and PVA were also carried along. Inside the droplet, a void was produced when the evaporation rate of moisture inside the droplet was higher than the diffusion rate through the droplet surface. When the pressure inside the droplet was higher than strength of dried surface layer, the explosion of droplet was not avoided, as shown in steps 2 and 3 in figure 13. In steps 4 and 5, the droplet shrank continuously due to the effect of surface tension until the donut-shaped feedstock formed. And the SEM image of typical donut-shaped feedstock was shown in figure 14 . So, the diffusion rate of moisture from the inside to the outside of the droplet played the most important role in the formation process of donutshaped feedstock. During the diffusion process of moisture, PVA carried by the moisture, would aggregate on the surface of droplet. Aggregation of PVA could hamper further diffusion of moisture that was still kept in the droplet, which resulted in the increases of the pressure inside the droplet and the number of donut-shaped feedstocks. Otherwise, if the inlet temperature was too high, it would decrease the particle size of feedstock, as shown in figure 7 . The reason was that the evaporation rate of moisture inside the droplet was higher than the diffusion rate through the droplet surface under high inlet temperature, which also resulted in the increase of the number of donut-shaped feedstocks.

\subsection{Optimal variables for spray drying}

Because the fluidity of donut-shaped feedstocks were worse than the spherical ones, it was better to avoid the formation of feedstocks with donut shape. Through the analysis on the effects of all the factors on the particle size and morphology of feedstock, the optimal variables for spray drying was identified. The result is listed in table 1. And SEM images of feedstocks after spray drying with optimal variables are shown in figure 15. As seen from it, all the feedstocks were solid spherical, which was expected to have a good fluidity for APS. The volume content of feedstocks with $10-45 \mu \mathrm{m}$ was above $65 \%$ and $D_{50}$ was $15.42 \mu \mathrm{m}$ according to LPSA.

\section{Conclusions}

In this paper, effects of variables concerning slurry properties and drying condition on the particle size and mor- 
phology of feedstock were discussed. The results indicated that the increase of powder loading increased $D_{50}$ and volume content but reduced recovery rate slightly. Other variables such as inlet temperature showed a maximum on the desired property. The particle size of resulting feedstock increased with the rise of feeding rate of slurry, however, decreased with the increase of atomization pressure based on the premise that atomization pressure was enough to force slurry to form the liquid membrane. For preparation of spherical feedstock, optimized variables were as follows: $60 \mathrm{wt} \%$ powder in slurry, 2 wt. $\%$ PVA in slurry, inlet temperature 1 of $60^{\circ} \mathrm{C}$, atomization pressure of $13 \times 10^{3} \mathrm{KPa}$ and feeding rate of $12 \mathrm{ml} \mathrm{min}^{-1}$. The volume content of feedstocks with $10-45 \mu \mathrm{m}$ was above $65 \%$ and $D_{50}$ was $15.42 \mu \mathrm{m}$. In addition, according to the heat and mass transfer equation, the drying mechanism was established, which was well in agreement with the experimental results.

\section{Acknowledgements}

This work was supported by the National Natural Science Foundation of China (Nos 50772086, 50821140308), and the High-Tech R\&D Program of China (863, No. 2007AA03Z558), and by Research Fund for the Doctoral
Program of Higher Education under contract No. 20060698008

\section{References}

Bertrand G, Roy P, Filiatre C and Coddet C 2005 Chem. Eng. Sci. 6095

Cao X Q, Vassen R, Schwartz S, Jungen W, Tietz F and Stoever D 2000 J. Eur. Ceram. Soc. 202433

Davis J R (ed.) 2004 Handbook of thermal spray technology (Materials Park, OH, USA: ASM International) p. 163

Edlmayr V, Moser M, Walter C and Mitterer C 2010 Surf. Coat. Technol. 2041576

Gretzinger J and Marshall W R Jr 1961 A.I.Ch.E.J. 7312

Hede P D, Bach P and Jensen A D 2008 Chem. Eng. Sci. 63 3821

Kathrein M, Schintlmeister W, Wallgram W and Schleinkofer U 2003 Surf. Coat. Technol. 163181

Keller N B, Bertrand G, Filiatre C, Meunier C and Coddet C 2003 Surf. Coat. Technol. 168281

Kollenberg W and Decker J 1993 Fresen. J. Anal. Chem. 346327

Liang H, Shinohara K, Minoshima H and Matsushima K 2001 Chem. Eng. Sci. $\mathbf{5 6} 2205$

Mahdjouba H, Roya P, Filiatreb C, Bertranda G and Coddeta C 2003 J. Eur. Ceram. Soc. 231637

Roy P, Bertrand G and Coddet C 2005 Powder Technol. 15720

Walton D E and Mumford C J 1999 Trans. Chem. 77452 